\title{
Can an mhealth clinical decision-making support system improve adherence to neonatal healthcare protocols in a low- resource setting?
}

Hannah Brown Amoakoh ${ }^{1,2^{*}}$ (D) Kerstin Klipstein-Grobusch ${ }^{1,3}$, Irene Akua Agyepong ${ }^{4}$, Mary Amoakoh-Coleman ${ }^{5}$, Gbenga A. Kayode ${ }^{1,6}$, J. B. Reitsma ${ }^{1}$, Diederick E. Grobbee ${ }^{1}$ and Evelyn K. Ansah ${ }^{7}$

\begin{abstract}
Background: This study assessed health workers' adherence to neonatal health protocols before and during the implementation of a mobile health (mHealth) clinical decision-making support system (mCDMSS) that sought to bridge access to neonatal health protocol gap in a low-resource setting.

Methods: We performed a cross-sectional document review within two purposively selected clusters (one poorlyresourced and one well-resourced), from each arm of a cluster-randomized trial at two different time points: before and during the trial. The total trial consisted of 16 clusters randomized into 8 intervention and 8 control clusters to assess the impact of an mCDMSS on neonatal mortality in Ghana. We evaluated health workers' adherence (expressed as percentages) to birth asphyxia, neonatal jaundice and cord sepsis protocols by reviewing medical records of neonatal in-patients using a checklist. Differences in adherence to neonatal health protocols within and between the study arms were assessed using Wilcoxon rank-sum and permutation tests for each morbidity type. In addition, we tracked concurrent neonatal health improvement activities in the clusters during the 18-month intervention period.

Results: In the intervention arm, mean adherence was 35.2\% (SD = 5.8\%) and 43.6\% (SD = 27.5\%) for asphyxia; 25.0\% $(S D=14.8 \%)$ and $39.3 \%(S D=27.7 \%)$ for jaundice; $52.0 \%(S D=11.0 \%)$ and $75.0 \%(S D=21.2 \%)$ for cord sepsis protocols in the pre-intervention and intervention periods respectively. In the control arm, mean adherence was 52.9\% (SD = $16.4 \%$ ) and $74.5 \%(S D=14.7 \%)$ for asphyxia; $45.1 \%(S D=12.8 \%)$ and $64.6 \%(S D=8.2 \%)$ for jaundice; $53.8 \%(S D=16.0 \%)$ and $60.8 \%$ (SD $=11.7 \%)$ for cord sepsis protocols in the pre-intervention and intervention periods respectively. We observed nonsignificant improvement in protocol adherence in the intervention clusters but significant improvement in protocol adherence in the control clusters. There were 2 concurrent neonatal health improvement activities in the intervention clusters and over 12 in the control clusters during the intervention period.

(Continued on next page)
\end{abstract}

\footnotetext{
* Correspondence: ansomaame@hotmail.com

'Julius Global Health, Julius Center for Health Sciences and Primary Care, University Medical Centre, Utrecht University, Utrecht, The Netherlands

${ }^{2}$ School of Public Health, University of Ghana, P.O. Box LG13, Legon, Accra, Ghana

Full list of author information is available at the end of the article
}

(c) The Author(s). 2020 Open Access This article is licensed under a Creative Commons Attribution 4.0 International License, which permits use, sharing, adaptation, distribution and reproduction in any medium or format, as long as you give appropriate credit to the original author(s) and the source, provide a link to the Creative Commons licence, and indicate if changes were made. The images or other third party material in this article are included in the article's Creative Commons licence, unless indicated otherwise in a credit line to the material. If material is not included in the article's Creative Commons licence and your intended use is not permitted by statutory regulation or exceeds the permitted use, you will need to obtain permission directly from the copyright holder. To view a copy of this licence, visit http://creativecommons.org/licenses/by/4.0/ The Creative Commons Public Domain Dedication waiver (http://creativecommons.org/publicdomain/zero/1.0/) applies to the data made available in this article, unless otherwise stated in a credit line to the data. 
(Continued from previous page)

Conclusion: Whether mHealth interventions can improve adherence to neonatal health protocols in low-resource settings cannot be ascertained by this study. Neonatal health improvement activities are however likely to improve protocol adherence. Future mHealth evaluations of protocol adherence must account for other concurrent interventions in study contexts.

Keywords: Health care delivery, Neonatal health, Ghana, mHealth, Developing countries, Jaundice, Asphyxia, Sepsis

\section{Background}

The Sustainable Development Goals aim to reduce the current high global neonatal mortality from 18 per 1000 to at least 12 per 1000 live births by 2030 [1]. Concerted effort is being harnessed through many international, national, district and community collaborations to make this a reality particularly in low-resource settings like sub-Saharan Africa and Southern Asia which contribute most to the global burden of neonatal mortality $[2,3]$. Infections, birth asphyxia and prematurity contribute to the majority of neonatal deaths in low-resource settings (90\%) [4]. Although morbidity and mortality from these conditions are largely preventable, the scarcity of health resources (facilities, personnel, basic equipment and medicines, training programmes, protocols etc.), allow these preventable deaths to thrive in the health systems of poorly resourced countries.

\section{Mobile health}

(mhealth) is a potential tool to improve the efficiency of health workers and the health system as a whole in lowresource settings [5]. Many mHealth interventions have been applied in areas of vaccination, management of tuberculosis and HIV, monitoring of antenatal health services for pregnant women in low-resource settings and have been documented to have variable but largely good success [6-9]. In the field of clinical decision-making support (CDMS), few mHealth interventions have been implemented in low-resource settings [9-16], and even fewer studies report adherence to protocols or algorithms specified by these electronic CDMS systems.

Ghana is a lower middle-income country that reports high neonatal mortality rates of 25 per 1000 live births [17]. Non-adherence to standard clinical protocols has been identified as a cause of Ghana's high neonatal mortality $[18,19]$. Previous studies have shown the absence of standard health protocols (the Safe Motherhood Protocol) for about $44 \%$ of health workers at the point of service delivery [20]. To bridge this protocol access gap, the Ghana Health Service (GHS) in collaboration with her Dutch partners designed and implemented an mHealth clinical decision-making support system (mCDMSS) aiming to improve clinical decision-making and ultimately neonatal health outcomes that was tested in a cluster randomized controlled trial (CRCT) in the Eastern Region of Ghana [21].

\section{Description of the intervention}

The mobile clinical decision making support intervention (THE INTERVENTION for short for the rest of this paper) consisted of 4 components - phone calls (voice), text messaging (SMS), access to the internet (data) and access to an unstructured supplementary service data (USSD) that provided emergency protocols in response to selection from a short code drop-down menu. The messages on the USSD were created by a design team of frontline health workers, family physicians, obstetricians and paediatricians in the Greater Accra Region, drawing on Ghana's Safe Motherhood Protocols [22]. All four components of the intervention were part of a single composite intervention delivered on a non-smart mobile phone. Researchers considered access to the USSD the main intervention component. Health workers were expected to use the phones primarily to access neonatal and maternal health emergency protocols via the USSD and obtain additional support from colleagues and the internet via the other intervention components. Each project mobile phone had a unique Subscriber Identification Module (SIM) card. All the SIM cards were networked in a Closed User Group (CUG) that allowed free and unlimited access to the USSD. Access to the intervention was, however, limited to the project SIM cards to avoid contamination. Health workers were trained on how to use the intervention firstly at a group gathering in each intervention district capital before the start of the CRCT and then at least once during monitoring visits in their individual health facilities during intervention implementation. Monthly reminders were also sent to health workers about the availability of the USSD platform for their use.

\section{Study objectives}

Our objectives in this study were to assess the quality of neonatal healthcare in the Eastern Region of Ghana, by examining the change in health worker adherence to neonatal health protocols in both study arms of the CRCT from a pre-intervention period to an intervention implementation period, and to investigate differences in adherence within and between the study arms during 
these time frames. We also assessed whether and which concurrent neonatal health improvement activities (not related to the intervention) occurred during the trial period. This study will provide insights to explain the observed effect of the intervention on neonatal mortality. For brevity, we limited this study to the neonatal component of the CRCT. Adherence to maternal health protocols during the CRCT will be published separately.

\section{Methods}

\section{Study design \& setting}

We designed a longitudinal study and performed a cross-sectional document review within two clusters selected from each arm of a cluster randomized trial at two different time points: before and during the trial. The trial aimed to assess the impact of an mCDMSS on neonatal mortality in the third most populous region in Ghana- the Eastern Region [23]. The trial was registered at clinicaltrials.gov (trial identifier number NCT02468310) and the Pan African Clinical Trials Registry (trial identification number PACT R20151200109073).

The Eastern Region has a neonatal mortality rate of 30 per 1000 live births and ranks fourth highest in terms of neonatal mortality in Ghana [24]. The region was divided into twenty-one (21) geographic local administrative units called districts at the time of the study. The CRCT was implemented over 18-months (August 2015 to January 2017) in 16 of these districts randomized into 8 intervention and 8 control clusters. Each of the 16 districts formed one cluster of the CRCT. The CRCT has been previously described elsewhere [25].

\section{Sampling of clusters}

For logistic reasons, one well-resourced and one poorlyresourced cluster were purposively selected from each CRCT arm making two clusters per arm. The selection criteria were based on the number and mix of health facilities (hospitals, community health planning and services compounds (CHPS), health centres ( $\mathrm{HCs}$ ) and maternity homes) in the district and the midwife to the number of deliveries (per annum) ratio in a district (reference year was 2014). Following cluster selection, district hospitals were sampled because initial assessment showed that almost all cases of neonatal morbidity of interest in this study were managed in the district hospitals.

\section{Recruitment of study participants}

All cases of in-patient neonatal morbidities of birth asphyxia, jaundice and cord sepsis that were managed in the district hospitals 9 months before the intervention started and, 9 months to the end of the intervention implementation period were studied to assess health worker adherence to protocols regarding morbidities. These morbidities were selected as the most common causes of neonatal morbidity in the study setting [26].

\section{Data collection}

Baseline data regarding the number and category of health workers providing neonatal health services in each cluster was collected using a checklist. We extracted data concerning the number of deliveries per study cluster during the two-time frames of interest from the district health information management system 2 (DHIMS2). The DHIMS2 is a data recording, collection, collation and analysis tool that hosts the entire national institutional health data of Ghana [21].

We utilized a scoring system based on existing health protocols as done in previous studies [27-29]. In each hospital, the head of the maternity or paediatric unit and the health information manager were contacted to identify the medical records (registers and books) that are routinely used in the hospitals to document in-patient neonatal data. A list of all in-patient cases of birth asphyxia, jaundice and cord sepsis was then populated from the 'in-patient admissions and discharge register' which documents all admitted cases in a hospital. A document review of the management of these cases was done using a checklist to assess health worker adherence to neonatal protocols. This checklist was based on Ghana's Safe Motherhood Protocol for management of neonatal morbidities. During data extraction, protocol items were assessed under the following themes where applicable for each morbidity type: i. Diagnosis (e.g., 'Diagnosis documented'), ii. Signs and symptoms of disease (e.g., 'Colour of baby', 'Cord assessed for odour, pus and wetness'), iii. Investigation (e.g., 'Serum bilirubin checked') iv. Treatment given (e.g., 'Airway of baby cleared through suction', 'Phototherapy given, or sunbath advised', 'Antibiotics given'). Assessment of adherence was only done for items that are considered mandatory in the management of each morbidity type (Tables 2, 3, 4). Additional file 1 details the type of facility records utilized in the data collection process.

Data concerning other concurrent neonatal health improvement interventions such as trainings and workshops that took place in the study districts during the 18-month intervention period was collected using a checklist. The district public health nurse in each cluster and the in-service trainers of the four hospitals assisted in extracting the relevant data from their facility record books.

\section{Data analysis}

The data were checked for errors, cleaned and analyzed at health facility level. We calculated the number of 
deliveries per midwife and doctor to estimate the delivery related workload in the study clusters. Descriptive analysis of neonatal data was performed. Items for each morbidity protocol was scored as 'adhered to' and assigned a score of 1 if there was written documentation of adherence to the item in any of the medical records. A protocol item was scored 'not adhered to' and assigned a score of zero (0) only when there was no written documentation of adherence in all the medical records. When the records of a neonate could not be traced because a register or book for a neonate was not found, protocol items were scored as 'don't know' and assigned a score of zero (0). Additional file 1 details the 'don't know' responses which totalled $2.9 \%$ of the entire data collected. For each item, the proportion of neonatal cases for whom guidelines were adhered to, was estimated. The mean and median adherence to protocols per morbidity type were calculated. Total adherence to specified neonatal morbidity protocol was estimated as the sum of scores per theme, presented as a percentage and rated (i.e. adherence status) high, moderate or low if total adherence was $90-100 \%, 89-60$ and $<60 \%$ respectively [30]. The difference in total adherence to neonatal protocols within and between the study arms during the time frame of interest was assessed using Wilcoxon rank-sum and permutation tests to determine the significance of these differences due to the small sample size. All analysis were done separately for the two time frames of interest (i.e., 9 months pre and 9 months to the end of the intervention) using two-tailed tests at $\alpha=$ 0.05 in Stata 13 [31].

We analysed the number, and described other activities aimed at improvement in neonatal health outcomes that were undertaken in both the intervention and control clusters during the intervention period.

\section{Results}

One district hospital in each of the four clusters participated in this study. Three of the hospitals were public owned and one was operated by a religious body. There were 2290 deliveries in the intervention arm hospitals and 4440 deliveries in the control arm hospitals in the pre-intervention period. During the intervention period, the number of deliveries stayed about the same in the intervention arm, whereas the number of deliveries increased by $20 \%$ in the control arm (Table 1). The number of deliveries per midwife was 76 and 109 in the intervention and control arm respectively during the pre-intervention period. During the intervention period, the number of deliveries per midwife was 66 and 115 in the intervention and control arm respectively. Cluster C recorded the highest delivery related workload during the pre and intervention periods. Table 1 details the characteristics, human resource availability and delivery related workload of the study clusters.

\section{Adherence to asphyxia protocols}

The prevalence of asphyxia was 3.5 and 15.1 per 1000 deliveries in the intervention and control arm respectively during the pre-intervention period. The 10th and 90th percentile for adherence per theme varied from $0 \%$ to $100 \%$ in the intervention arm and $33.3 \%$ to $100 \%$, in the control arm in this time frame (see Table 2). In the intervention arm, the mean score for total adherence to asphyxia protocols was $35.2 \%(\mathrm{SD}=5.8 \%)$ and in the control arm, it was $52.9 \%(\mathrm{SD}=16.4 \%)$.

During the intervention period, the prevalence of asphyxia was 6 and 9.4 per 1000 deliveries in the intervention and control clusters respectively. The range of values for the 10th and 90th percentile for adherence per theme remained the same during the intervention period. The mean total adherence was $43.6 \%(\mathrm{SD}=$ $27.5 \%)$ in the intervention arm, and in the control arm, it was $74.5 \%(\mathrm{SD}=14.7 \%)$.

Adherence status to asphyxia protocols was moderate to low in the pre-intervention period and high to low in the intervention period (Fig. 1). Overall, there was improvement in total adherence to asphyxia protocols in both study arms $(23.9 \%$ and $40.8 \%$ in the intervention and control clusters respectively). However, improvement in the intervention arm (Fig. 2) was not significant $(p=0.92)$ while improvement in the control arm was significant $(p<0.001)$. Between the study arms, the control arm sites were more adherent to asphyxia protocols compared to the intervention arm before and during the trial period ( $p=0.002$ and $p<0.001$ respectively).

\section{Adherence to jaundice protocols}

There were 2.6 and 6.5 cases of jaundice per 1000 deliveries in the intervention and control arms respectively during the pre-intervention period. Jaundiced neonates were on average 7.2 days old ( $\mathrm{SD}=7.3$ days). The 10th and 90th percentile for adherence per theme for jaundice protocol varied from $0 \%$ to $100 \%$ in both study arms (Table 3). The mean total adherence to jaundice protocols was $25.0 \%(\mathrm{SD}=14.8 \%)$ in the intervention $\mathrm{arm}$, and in the control arm it was $45.1 \%(\mathrm{SD}=12.8 \%$ ). The cause of jaundice was not identified in $65.7 \%$ of cases; in $30.4 \%$ of cases, glucose-6-phosphate-dehydrogenase deficiency (G6PD deficiency) was the cause of jaundice and gastroenteritis in one case. Four jaundiced neonates (two in each arm) received no counselling for sunbathing, neither were they put in a phototherapy unit. Two of four neonates in the control arm whose caretakers were advised to give their babies sunbath were not followed up as per protocol. Most jaundiced neonates $(33(91.4 \%))$ received antibiotic as part of their 
Table 1 Distribution of health personnel and delivery related workload in study clusters

\begin{tabular}{|c|c|c|c|c|c|c|c|c|}
\hline \multirow[t]{2}{*}{ Period } & \multirow[t]{2}{*}{ Cluster } & \multirow[t]{2}{*}{$\begin{array}{l}\text { Resource } \\
\text { ranking }\end{array}$} & \multirow[t]{2}{*}{$\begin{array}{l}\text { Operating } \\
\text { authority }\end{array}$} & \multirow{2}{*}{$\begin{array}{l}\text { Number of } \\
\text { doctors } \\
\text { (n) }\end{array}$} & \multirow{2}{*}{$\begin{array}{l}\text { Number of } \\
\text { obstetricians } \\
\text { (n) }\end{array}$} & \multirow{2}{*}{$\begin{array}{l}\text { Number of } \\
\text { paediatricians } \\
\text { (n) }\end{array}$} & \multirow{2}{*}{$\begin{array}{l}\text { Number of } \\
\text { midwives } \\
\text { (n) }\end{array}$} & \multirow[t]{2}{*}{$\begin{array}{l}\text { Number of } \\
\text { deliveries }\end{array}$} \\
\hline & & & & & & & & \\
\hline \multirow[t]{6}{*}{$\begin{array}{l}\text { Pre- } \\
\text { trial }\end{array}$} & $\begin{array}{l}\text { Intervention } \\
\text { arm }\end{array}$ & & & & & & & \\
\hline & A & $\begin{array}{l}\text { High } \\
\text {-resource }\end{array}$ & Government & 4 & 0 & 0 & 21 & 1636 \\
\hline & B & $\begin{array}{l}\text { Low- } \\
\text { resource }\end{array}$ & Religious & 1 & 0 & 0 & 9 & 654 \\
\hline & Control arm & & & & & & & \\
\hline & C & $\begin{array}{l}\text { High } \\
\text {-resource }\end{array}$ & Government & 7 & 0 & 0 & 29 & 3569 \\
\hline & D & $\begin{array}{l}\text { Low- } \\
\text { resource }\end{array}$ & Government & 2 & 0 & 0 & 10 & 671 \\
\hline \multirow[t]{6}{*}{ Trial } & $\begin{array}{l}\text { Intervention } \\
\text { arm }\end{array}$ & & & & & & & \\
\hline & A & $\begin{array}{l}\text { High } \\
\text {-resource }\end{array}$ & Government & 5 & 0 & 0 & 23 & 1759 \\
\hline & B & $\begin{array}{l}\text { Low- } \\
\text { resource }\end{array}$ & Religious & 2 & 1 & 0 & 15 & 735 \\
\hline & Control arm & & & & & & & \\
\hline & C & $\begin{array}{l}\text { High } \\
\text {-resource }\end{array}$ & Government & 5 & 0 & 0 & 34 & 4657 \\
\hline & D & $\begin{array}{l}\text { Low- } \\
\text { resource }\end{array}$ & Government & 3 & 0 & 0 & 13 & 768 \\
\hline Period & Cluster & $\begin{array}{l}\text { Resource } \\
\text { ranking }\end{array}$ & $\begin{array}{l}\text { Deliveries per } \\
\text { midwife }\end{array}$ & $\begin{array}{l}\text { Deliveries per } \\
\text { doctor }\end{array}$ & ${ }^{\mathrm{a}}$ Workload & Proportion of & and post inte & ntion deliveries \\
\hline \multirow[t]{6}{*}{$\begin{array}{l}\text { Pre- } \\
\text { trial }\end{array}$} & $\begin{array}{l}\text { Intervention } \\
\text { arm }\end{array}$ & & & & & & & \\
\hline & A & $\begin{array}{l}\text { High } \\
\text {-resource }\end{array}$ & 78 & 409 & Moderate & 0.25 & & \\
\hline & B & $\begin{array}{l}\text { Low- } \\
\text { resource }\end{array}$ & 73 & 654 & Moderate & 0.22 & & \\
\hline & Control arm & & & & & & & \\
\hline & C & $\begin{array}{l}\text { High } \\
\text {-resource }\end{array}$ & 123 & 510 & High & 0.55 & & \\
\hline & D & $\begin{array}{l}\text { Low- } \\
\text { resource }\end{array}$ & 67 & 336 & Moderate & 0.10 & & \\
\hline \multirow[t]{6}{*}{ Trial } & $\begin{array}{l}\text { Intervention } \\
\text { arm }\end{array}$ & & & & & & & \\
\hline & A & $\begin{array}{l}\text { High } \\
\text {-resource }\end{array}$ & 76 & 352 & High & 0.22 & & \\
\hline & B & $\begin{array}{l}\text { Low- } \\
\text { resource }\end{array}$ & 49 & 368 & low & 0.09 & & \\
\hline & Control arm & & & & & & & \\
\hline & C & $\begin{array}{l}\text { High } \\
\text {-resource }\end{array}$ & 137 & 931 & High & 0.59 & & \\
\hline & $\mathrm{D}$ & $\begin{array}{l}\text { Low- } \\
\text { resource }\end{array}$ & 59 & 256 & Moderate & 0.10 & & \\
\hline
\end{tabular}

${ }^{a}$ Estimated by the number of deliveries per midwife; Low $<50$, Moderate $50-90$, High $>90$. The workload in each cluster is higher than the internationally recognized value of 29.5 per midwife. The categorization of workload used here is based solely on comparison between the estimated workload among the study clusters 
Table 2 Total adherence score and proportion of asphyxia protocol items adhered to before and during intervention implementation

\begin{tabular}{|c|c|c|c|c|}
\hline \multirow[t]{2}{*}{ Protocol item } & \multicolumn{2}{|c|}{ aPre-trial period $(N=75)$} & \multicolumn{2}{|c|}{${ }^{\mathrm{b}}$ Trial period $(N=66)$} \\
\hline & $\begin{array}{l}\text { Intervention } \\
\mathrm{n}(\%)\end{array}$ & $\begin{array}{l}\text { Control } \\
\text { n (\%) }\end{array}$ & $\begin{array}{l}\text { Intervention } \\
\mathrm{n}(\%)\end{array}$ & $\begin{array}{l}\text { Control } \\
\mathrm{n}(\%)\end{array}$ \\
\hline \multicolumn{5}{|l|}{ Diagnosis } \\
\hline Diagnosis documented & $8(100.0)$ & $66(98.5)$ & $14(93.3)$ & $51(100.0)$ \\
\hline \multicolumn{5}{|l|}{ Signs and symptoms } \\
\hline Description of difficulty in breathing & $0(0.0)$ & $14(20.9)$ & $7(46.7)$ & $16(32.0)$ \\
\hline Heart rate neonate recorded & $0(0.0)$ & $5(7.5)$ & $4(26.7)$ & $48(94.1)$ \\
\hline Tachycardia & $0(0.0)$ & $11(16.4)$ & $4(26.7)$ & $48(94.1)$ \\
\hline Respiratory rate & $0(0.0)$ & $45(67.2)$ & $5(33.3)$ & $48(94.1)$ \\
\hline Colour of baby & $0(0.0)$ & $25(37.3)$ & $5(33.3)$ & $45(88.2)$ \\
\hline APGAR scores written & $8(100.0)$ & $63(94.0)$ & $14(93.3)$ & $48(94.1)$ \\
\hline Liquor assessed for meconium staining & $2(25.0)$ & $21(31.3)$ & $4(26.7)$ & $8(15.7)$ \\
\hline \multicolumn{5}{|l|}{ Treatment } \\
\hline Airway of neonate cleared through suction & $1(12.5)$ & $42(62.7)$ & $4(26.7)$ & $14(27.5)$ \\
\hline Warmth provided (using incubator or wrapping) & $7(87.5)$ & $43(64.2)$ & $2(13.3)$ & $43(84.3)$ \\
\hline Oxygen given / Bag and mask resuscitation & $5(62.5)$ & $55(82.1)$ & $9(60.0)$ & $49(96.1)$ \\
\hline \multicolumn{5}{|l|}{ Total adherence score } \\
\hline 1 & - & - & $1(6.7)$ & - \\
\hline 2 & - & $3(4.5)$ & $3(20.0)$ & $1(2.0)$ \\
\hline 3 & $2(25.0)$ & $6(9.0)$ & $3(20.0)$ & $2(3.9)$ \\
\hline 4 & $5(62.5)$ & $7(10.5)$ & $1(6.7)$ & - \\
\hline 5 & $1(12.5)$ & $10(14.9)$ & $3(20.0)$ & - \\
\hline 6 & - & $14(20.9)$ & - & - \\
\hline 7 & - & $13(19.4)$ & - & $3(5.9)$ \\
\hline 8 & - & $13(19.4)$ & - & $23(45.1)$ \\
\hline 9 & - & $1(1.5)$ & $3(20.0)$ & 15 (29.4) \\
\hline 10 & - & - & $1(6.7)$ & 7 (13.73) \\
\hline
\end{tabular}

There were 2290 and 4440 deliveries in the intervention and control arm respectively in the pre-trial period

${ }^{\mathrm{b}}$ There were 2494 and 5425 deliveries in the intervention and control arm respectively in the trial period
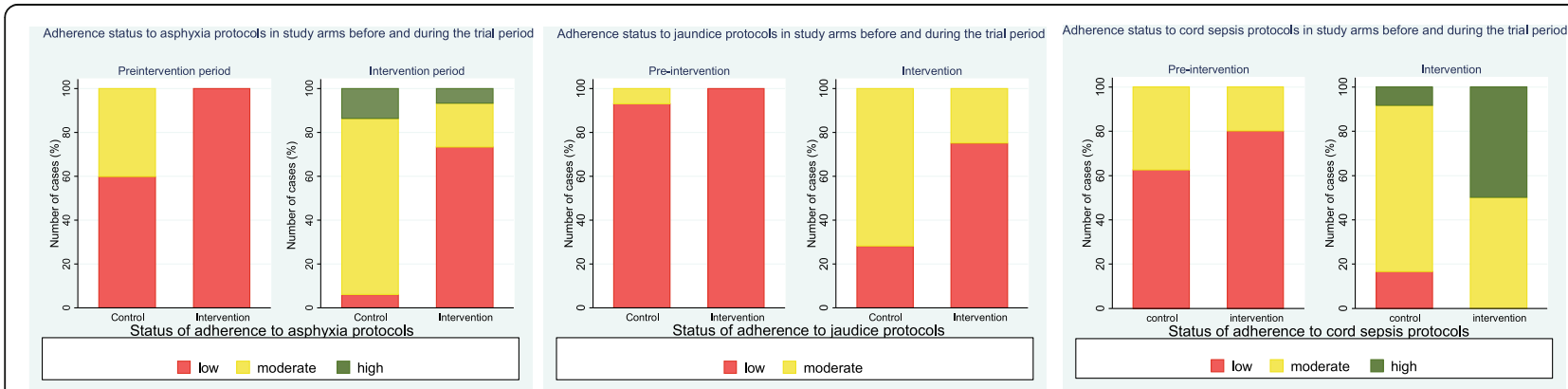

Fig. 1 Adherence status per morbidity type before and during the intervention period 


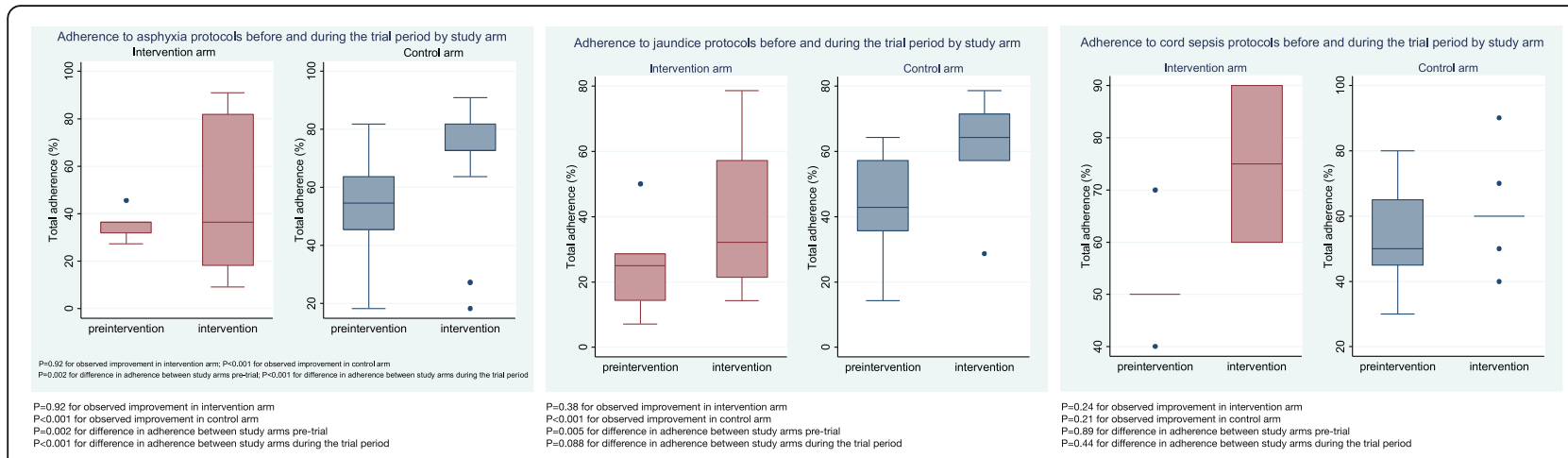

Fig. 2 Distribution and change in total adherence to asphyxia, jaundice and cord sepsis protocols among study clusters

treatment although there was only one documented case of infection (gastroenteritis).

The number of jaundiced neonates decreased to 1.6 per 1000 deliveries in the intervention arm and increased to 9.2 per 1000 deliveries in the control arm during the intervention period. These jaundiced neonates were on average 5.1 days ( $\mathrm{SD}=4.5$ days) old at the time of the diagnosis. The 10th and 90th percentile for adherence per theme for jaundice protocol varied from $0 \%$ to $100 \%$ in intervention arm and $14.3 \%$ to $100 \%$ in the control arm. In the intervention arm, the mean score for total adherence to jaundice protocols was 39.3\% $(\mathrm{SD}=27.7 \%)$; in the control arm it was $64.6 \%(\mathrm{SD}=$ $8.2 \%)$. In 45 (83.3\%) of all cases of jaundice, the cause of the jaundice was classified 'unknown'. One case of physiological jaundice and one case of pathological jaundice were identified in the intervention arm, while one case of cord sepsis and one case of physiological jaundice were identified in the control arm; for the rest of the cases, the cause of the jaundice was not stated in any of the records found in the health facilities. There was no documentation of treatment (using phototherapy or by sun-bathing) of three neonates in the intervention clusters. In the control clusters, all jaundiced neonates received either of the aforementioned treatment options. All sunbathed neonates were followed up during the intervention period. All jaundiced neonates received antibiotics as part of their treatment although only one case of infection (cord sepsis) was identified as a cause of jaundice.

Overall, adherence status was low to moderate during the pre-intervention and intervention periods (Fig. 1). The $57.2 \%$ improvement in adherence to jaundice protocols observed in the intervention clusters (Fig. 2) was not significant $(p$-value $=0.38$ ) while improvement observed in the control clusters (43.2\%) was significant ( $p$ value $<0.001$ ). Comparing the two study arms, control clusters scored higher in adherence to jaundice protocols before and during the intervention period ( $p$-value $=$ 0.005 and 0.088 respectively).

\section{Adherence to cord sepsis protocols}

The prevalence of cord sepsis was 2.2 and 1.8 per 1000 deliveries in the intervention and control arms in the pre-intervention period. The average age of these neonates was 5.4 days $(\mathrm{SD}=3.8$ days). The 10th and 90th percentile for adherence per theme for cord sepsis protocol varied from $16.7 \%$ to $100 \%$ in both study arms (Table 4). Altogether, the mean total adherence to cord sepsis protocols in the intervention arm was $52.0 \%$ ( $\mathrm{SD}=$ $11.0 \%)$ and, $53.8 \%(\mathrm{SD}=16.0 \%)$ in the control clusters.

There were 0.8 and 2.2 cases of cord sepsis per 1000 deliveries during intervention implementation. The average age of these neonates was 5.9 days $(\mathrm{SD}=4.9$ days). Altogether, the mean total adherence to cord sepsis protocols in the intervention arm was $75.0 \%(\mathrm{SD}=21.2 \%)$ whereas, in the control arm, it was $60.8 \%(\mathrm{SD}=11.7 \%)$. The 10th and 90th percentile for adherence per theme for cord sepsis protocol varied from $50 \%$ to $100 \%$ in the intervention arm and $33.3 \%$ to $100 \%$ in the control arm.

Adherence status was low to moderate during the preintervention and intervention periods (Fig. 1). Improvement in adherence to protocols was observed in both study arms $(44.2 \%$ and $13 \%$ in intervention and control arms respectively) (Fig. 2). However, these improvements were not significant $(p=0.24$ and $p=0.21$ for intervention and control arms respectively). Between the study arms, adherence to cord sepsis protocols were not significantly different $(p=0.89$ and $p=0.44$ for intervention and control arms respectively).

\section{Concurrent neonatal health activities in clusters}

In the intervention clusters, there were two training programmes that were aimed at improving neonatal health outcomes during the intervention period while in the control clusters, training programmes aimed at improving neonatal health numbered more than 12 (Table 5). Eight of these trainings (two in the intervention clusters and six in the control clusters) were intensive exercises aimed at improving new-born resuscitation and lasted six (6) to seven (7) days. These intensive training 
Table 3 Total adherence score and proportion of jaundice protocol items adhered to before and during intervention implementation

\begin{tabular}{|c|c|c|c|c|}
\hline \multirow[t]{2}{*}{ Protocol item } & \multicolumn{2}{|c|}{ 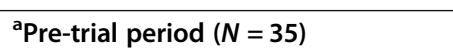 } & \multicolumn{2}{|c|}{${ }^{\mathrm{b}}$ Trial period $(N=54)$} \\
\hline & $\begin{array}{l}\text { Intervention } \\
\mathrm{n}(\%)\end{array}$ & $\begin{array}{l}\text { Control } \\
\text { n (\%) }\end{array}$ & $\begin{array}{l}\text { Intervention } \\
\mathrm{n}(\%)\end{array}$ & $\begin{array}{l}\text { Control } \\
\mathrm{n}(\%)\end{array}$ \\
\hline \multicolumn{5}{|l|}{ Diagnosis } \\
\hline Diagnosis documented & $6(100.0)$ & $29(100.0)$ & $4(100.0)$ & $50(100.0)$ \\
\hline \multicolumn{5}{|l|}{ Signs and symptoms } \\
\hline Duration of jaundice stated & $0(0.0)$ & $8(27.6)$ & $3(75.0)$ & $46(92.0)$ \\
\hline Temperature checked & $3(50.0)$ & $14(14.3)$ & $2(50.0)$ & $11(22.0)$ \\
\hline Assessed for vomiting & $1(25.0)$ & $5(17.2)$ & $2(50.0)$ & $1(2.0)$ \\
\hline Assessed for episode(s) of convulsion & $1(25.0)$ & $0(0.0)$ & $2(50.0)$ & $0(0.0)$ \\
\hline Assessed for poor feeding & $3(60.0)$ & $3(10.3)$ & $2(50.0)$ & $21(42.0)$ \\
\hline Assessed for excessive crying & $1(25.0)$ & $2(6.9)$ & $1(25.0)$ & $28(56.0)$ \\
\hline Assessed for hypotonia & $0(0.0)$ & $0(0.0)$ & $0(0.0)$ & $2(4.0)$ \\
\hline \multicolumn{5}{|l|}{ Investigation } \\
\hline Full blood count done & $2(33.3)$ & $26(89.7)$ & $2(50.0)$ & $49(98.0)$ \\
\hline Blood grouping checked & $0(0.0)$ & $22(75.9)$ & $1(25.0)$ & $49(98.0)$ \\
\hline Serum bilirubin checked & $0(0.0)$ & $21(72.4)$ & $1(25.0)$ & $49(98.0)$ \\
\hline Samples for blood cultures taken & $0(0.0)$ & $8(27.6)$ & $1(25.0)$ & $47(94.0)$ \\
\hline Samples for G6PD deficiency screen taken & $0(0.0)$ & $18(62.1)$ & $0(0.0)$ & $49(98.0)$ \\
\hline \multicolumn{5}{|l|}{ Treatment } \\
\hline Phototherapy given or sunbath advised & $4(66.7)$ & $27(93.1)$ & $1(25.0)$ & $50(100.0)$ \\
\hline \multicolumn{5}{|l|}{ Total adherence score } \\
\hline 1 & $1(16.7)$ & - & - & - \\
\hline 2 & $1(16.7)$ & $1(3.5)$ & $1(25.0)$ & - \\
\hline 3 & $1(16.7)$ & $2(6.9)$ & - & - \\
\hline 4 & $2(33.3)$ & $1(3.5)$ & $1(25.0)$ & $1(2.0)$ \\
\hline 5 & & $4(13.8)$ & $1(25.0)$ & - \\
\hline 6 & & $7(24.1)$ & - & - \\
\hline 7 & $1(16.7)$ & $5(17.2)$ & - & - \\
\hline 8 & & $7(24.1)$ & - & $13(26.0)$ \\
\hline 9 & & $2(6.9)$ & - & $19(38.0)$ \\
\hline 10 & & - & - & $14(28.0)$ \\
\hline 11 & & - & $1(25.0)$ & $3(6.0)$ \\
\hline
\end{tabular}

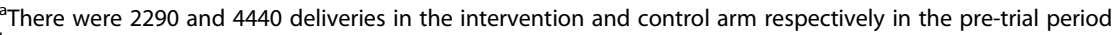

${ }^{\mathrm{b}}$ There were 2494 and 5425 deliveries in the intervention and control arm respectively in the trial period

programmes were organized by a non-governmental agency. The rest of the training programmes in the control clusters usually lasted for one (1) day.

\section{Discussion}

\section{Adherence to asphyxia protocols}

We observed fairly good adherence to asphyxia diagnosis protocol in this study. However, adherence to 'signs and symptoms' protocols was sub-optimal in both study clusters particularly in the pre-intervention period. Several of the 'signs and symptoms' assessments culminates in the APGAR score of neonates [32]. Not assessing these signs and symptoms can lead to inaccurate APGA $\mathrm{R}$ scores and inappropriate treatment of neonates who require resuscitation. Surprisingly, the APGAR scores were usually documented, thus one could argue that these signs and symptoms assessments were done but not documented because the natural focus is to treat the patient and not record [33], however, video recording of neonatal resuscitation has shown otherwise [33-35]. In the intervention clusters, adherence to treatment protocols worsened during the intervention period. Lack of 
Table 4 Total adherence score and proportion of cord sepsis protocol items adhered to before and during intervention implementation

\begin{tabular}{|c|c|c|c|c|}
\hline \multirow[t]{2}{*}{ Protocol item } & \multicolumn{2}{|c|}{${ }^{\text {a }}$ Pre-trial period $(N=13)$} & \multicolumn{2}{|c|}{${ }^{\mathrm{b}}$ Trial period $(N=14)$} \\
\hline & $\begin{array}{l}\text { Intervention } \\
\mathrm{n}(\%)\end{array}$ & $\begin{array}{l}\text { Control } \\
\text { n (\%) }\end{array}$ & $\begin{array}{l}\text { Intervention } \\
\mathrm{n}(\%)\end{array}$ & $\begin{array}{l}\text { Control } \\
\mathrm{n}(\%)\end{array}$ \\
\hline \multicolumn{5}{|l|}{ Diagnosis } \\
\hline Diagnosis documented & $5(100.0)$ & $8(100.0)$ & $2(100.0)$ & $12(100.0)$ \\
\hline \multicolumn{5}{|l|}{ Signs and symptoms } \\
\hline Cord assessed for odor, pus and wetness & $3(60.00)$ & $2(25.0)$ & $1(50.0)$ & $9(75.0)$ \\
\hline Skin around cord assessed for redness & $2(40.0)$ & $3(37.5)$ & $0(0.0)$ & $4(33.3)$ \\
\hline Assessment for fever & $3(60.0)$ & $5(62.5)$ & $1(50.0)$ & $3(25.0)$ \\
\hline Heart rate, pulse rate, respiratory rate & $2(40.0)$ & $7(87.5)$ & $2(100.0)$ & $11(91.7)$ \\
\hline Abdomen palpated & $0(0.00)$ & $2(25.0)$ & $2(100.0)$ & $5(41.7)$ \\
\hline Conjunctiva or haemoglobin checked & $0(0.00)$ & $1(12.5)$ & $2(100.0)$ & $1(8.3)$ \\
\hline \multicolumn{5}{|l|}{ Treatment } \\
\hline Cord hygiene education given to mother & $2(40.0)$ & $0(0.0)$ & $1(50.0)$ & $5(41.7)$ \\
\hline Antibiotics given & $5(100.0)$ & $8(100.0)$ & $2(100.0)$ & $12(100.0)$ \\
\hline Monitoring of vitals & $4(80.0)$ & $7(87.5)$ & $2(100.0)$ & $11(91.7)$ \\
\hline \multicolumn{5}{|l|}{ Total adherence score } \\
\hline 1 & - & - & - & - \\
\hline 2 & - & - & - & - \\
\hline 3 & - & $1(12.5)$ & - & - \\
\hline 4 & $1(20.0)$ & $1(12.5)$ & - & $1(8.3)$ \\
\hline 5 & $3(60.0)$ & $3(37.5)$ & - & $1(8.3)$ \\
\hline 6 & & $1(12.5)$ & $1(50.0)$ & $8(66.7)$ \\
\hline 7 & $1(20.0)$ & $1(12.5)$ & - & $1(8.3)$ \\
\hline 8 & & $1(12.5)$ & - & - \\
\hline 9 & & - & $1(50.0)$ & - \\
\hline 10 & & - & - & $1(8.3)$ \\
\hline
\end{tabular}

${ }^{\text {a There were }} 2290$ and 4440 deliveries in the intervention and control arm respectively in the pre-trial period

${ }^{\text {b}}$ There were 2494 and 5425 deliveries in the intervention and control arm respectively in the trial period

knowledge about asphyxia as documented in Malawi could be an explanation for this observation [36]. The intervention (mCDMSS) was intended to bridge such knowledge gap, however, the absence of knowledge transfer (about the intervention) implies persistence of lack of knowledge and access gap in the intervention clusters possibly through suboptimal use of the intervention [37]. Monthly reminders concerning the availability of the mCDMSS for the use of health workers and, retraining of health workers at post in health facilities

Table 5 Concurrent neonatal health improvement activities in study clusters during the intervention period

\begin{tabular}{|c|c|c|c|c|}
\hline Arm & Cluster & $\begin{array}{l}\text { Resource } \\
\text { ranking }\end{array}$ & $\begin{array}{l}\text { Total number } \\
\text { of activities }\end{array}$ & Activities/topics discussed \\
\hline Intervention & A & High & 1 & Making every baby count initiative \\
\hline Intervention & B & Low & 1 & Making every baby count initiative \\
\hline Control & C & High & $>7$ & $\begin{array}{l}\text { Policy on breast feeding and Hepatitis exposed babies; Assisted Vacuum Delivery; }{ }^{\text {a Helping }} \\
\text { babies breathe training; Bi-weekly continuous professional training aimed at reducing the in- } \\
\text { cidence of birth asphyxia and improving new-born resuscitation }\end{array}$ \\
\hline Control & D & Low & 5 & $\begin{array}{l}\text { Accelerating the achievement of Millennium Development Goal 4; Provider training; Helping } \\
\text { babies breathe and essential care for every baby; 7th District Hospital provider training; } \\
\text { Maternal and Neonatal audit workshop }\end{array}$ \\
\hline
\end{tabular}

${ }^{a}$ There were a total of at least 5 rounds of this training with a new group of midwives being trained each time 
during supervisory visits by the project team, seem not to have been effective in addressing the challenge of suboptimal use of the intervention [37]. Poor adherence as observed suggests focused support for health workers in the management of asphyxia in order to improve adherence to its protocols.

\section{Adherence to jaundice protocols}

Protocols for management of Jaundice were least adhered to among the three morbidity protocols understudied. There was poor adherence to protocol items for the theme 'Signs and symptoms' of jaundice in all clusters in both time frames. Of note is the assessment of neonates for convulsion and hypotonia. While the diagnosis of convulsion may be difficult in neonates [38, 39], hypotonia can be objectively assessed; the lack of documented evidence of assessment of these two critical signs of the central nervous system (CNS) is undesirable given disabilities associated with CNS complications (kernicterus) from jaundice [40]. Failure of the health workers to recognize at-risk infants and poor management of hyperbilirubinemia is a known cause of kernicterus [40]. The observed complete non-adherence to jaundice investigation protocols in the intervention arm during the pre-intervention period and poor adherence to these protocols in the intervention period could be due to the absence of the rapid tests or laboratory equipment to run these tests in the hospitals. Lack of required equipment is associated with non-adherence to protocols [41-43]. Neonates with mild jaundice may have been the ones not treated in this study; the absence of follow-up of jaundiced neonates has been previously documented and can be associated with dire consequences should the jaundice worsen [40]. We report indiscriminate use of antibiotics in cases of jaundice and this suggests the need for training on rational use of antibiotics in the study setting.

\section{Adherence to cord sepsis protocols}

Prevalence of cord sepsis in this study was low. This may be due to on-going interventions in the GHS to promote good cord hygiene practises [44, 45]. This low prevalence of cord sepsis may however lead to poor recall of assessments for cord sepsis cases as observed in the low adherence score for 'signs and symptoms' in this study. Local signs of cord sepsis (e.g. pus and odour) are associated with mortality [46], therefore lack of assessment for these local 'signs and symptoms' can be potentially catastrophic for neonates as important complications from the cord infection that may warrant urgent attention or treatment modification may be missed. All cases of cord sepsis were treated with antibiotics which indicates that once a diagnosis is made, treatment will be initiated, and the vitals of patients will be monitored as observed. The non-adherence to protocol item regarding cord hygiene education for caregivers presents a missed opportunity to teach cord hygiene in a setting where poor cord hygiene still exists in some communities [47]. Caregivers are known to be inappropriately educated by health workers about the morbidities, treatment and associated complications their wards may experience [40, 41].

\section{Adherence to protocols in general}

We found no case of complete adherence to protocols for all three morbidity types (asphyxia, jaundice, and cord sepsis) in this study using data of 257 neonates in the four district hospitals. A similar observation was made in another study where every resuscitation had an error [33]. Improvement in adherence to all three morbidity type protocols during the intervention period in both the control and intervention arms is possibly due to training programmes of the GHS and her partners in this area. Such efforts must be documented and reviewed to optimize their effect on improvement in neonatal healthcare services. Cluster $\mathrm{C}$ recorded the highest proportion of deliveries, and the highest workload but the best adherence to protocols before and during the intervention period. Low workloads can influence competence and high workloads can influence ability to respond adequately; the high workload of cluster $\mathrm{C}$ could have positively influenced the cluster's observed adherence to protocols.

\section{Contribution of concurrent activities to improvements adherence to neonatal care protocols}

"Even if you know everything you can forget" [48]. Frequent reminders, trainings and refresher trainings are a means to improve health outcomes in general. The observed higher improvements in adherence to protocols in the control clusters compared to the intervention clusters may reflect differences in knowledge across the intervention and control clusters resulting from the training programmes that were more frequently undertaken by hospital management, the GHS and her partners in control clusters. Commensurate efforts on neonatal health improvement training programmes in addition to the mCDMSS in the intervention clusters may have led to significant improvements in adherence to protocols in the intervention clusters as well. The higher number of concurrent neonatal health improvement activities in the control clusters could also explain the observed lower odds of neonatal death in the main CRCT findings [49].

\section{Limitation}

We sought to understand the pattern of health worker adherence to neonatal health protocols before and 
during the implementation of an mCDMSS, but our study has certain limitations. Differences in adherence to protocols by resource allocation type per study arm were not assessed. Due to the low incidence of cases among the various subgroups and because individual level data concerning mortality was incomplete in the DHIMS2 and in the health facility medical records, we could not control for the effect of the concurrent neonatal improvement activities in our analysis, nor analyse the relationship between adherence and neonatal mortality as originally indicated in our trial registration. The results of our study should therefore be interpreted in the light of these methodological limitations. We did not evaluate the type of health care provider in relation to the care provided nor the factors that may have influenced adherence to neonatal protocols. Qualitative analyses of why the observed pattern of adherence occurred could have provided more insight into the results we have obtained and are recommended for future studies.

\section{Conclusion}

The question of whether mHealth interventions can improve adherence to neonatal health protocols in a low-resource setting remains difficult to answer from the evidence generated in this study, but, during the study, adherence improved irrespective of intervention allocation. This was particularly observed for the control clusters, and concurrent neonatal improvement interventions that took place in the study clusters may explain this effect. It is therefore essential to document and review all ongoing interventions whose goals are to improve health worker adherence to neonatal health protocols in study settings. Concurrent neonatal health improvement activities must be taken into account in similar mHealth evaluations. Future studies should relate adherence with patient outcomes.

\section{Supplementary information}

Supplementary information accompanies this paper at https://doi.org/10. 1186/s12887-020-02378-1.

\section{Additional file 1.}

\section{Abbreviations}

CDMS: Clinical decision-making support; CHPS: Community based health planning and services; CNS: Central nervous system; CRCT: Cluster randomized controlled trial; CUG: Closed user group; DHIMS2: District health information management system 2; G6PD: Glucose-6- phosphate dehydrogenase deficiency; GHS: Ghana health service; HCs: Health centres; mCDMSS: Mhealth clinical decision-making support system; SIM: Subscriber identification module; SMS: Short message system; USSD: Unstructured supplementary service data

\section{Acknowledgements}

The authors thank the Ghana Health Service Research and Development Division, the Eastern Region Health Directorate, members of the district health management teams in the Eastern Region and the School of Public Health, University of Ghana for their support in the conduct of this study.

\section{Authors' contributions}

$\mathrm{HBA}, \mathrm{KKG}, \mathrm{MAC}, \mathrm{KAG}$, and EA designed and performed the study. HBA drafted the manuscript and KKG, EA reviewed the manuscript. IAA, DEG, MAC, KAG, JBR, provided critical comments on the review of the manuscript. All authors have read and approved the final manuscript.

\section{Funding}

Netherlands Foundation for Scientific Research, Global Health Policy and Health Systems Research Program (Grant Number: 07.45.102.00) and Utrecht University, Netherlands.

\section{Availability of data and materials \\ Data for this study is available on request by emailing the corresponding author at ansomaame@hotmail.com.}

Ethics approval and consent to participate

This study was approved by the Ghana Health Service Ethics Review Committee (approval number number: GHS-ERC: 04/09/16). Institutional heads of the various hospitals consented for their hospitals to participate in this study.

\section{Consent for publication}

Not applicable.

\section{Competing interests}

None declared.

\section{Author details}

'Julius Global Health, Julius Center for Health Sciences and Primary Care, University Medical Centre, Utrecht University, Utrecht, The Netherlands. ${ }^{2}$ School of Public Health, University of Ghana, P.O. Box LG13, Legon, Accra, Ghana. ${ }^{3}$ Division of Epidemiology and Biostatistics, School of Public Health, Faculty of Health Sciences, University of the Witwatersrand, Johannesburg, South Africa. ${ }^{4}$ Research and Development Division, Ghana Health Service, Dodowa, Accra, Ghana. ${ }^{5}$ Noguchi Memorial Institute, University of Ghana, Legon, Accra, Ghana. ${ }^{6}$ International Research Centre of Excellence, Institute of Human Virology, Abuja, Nigeria. ${ }^{7}$ University of Health and Allied Sciences, Ho, Ghana.

Received: 9 June 2019 Accepted: 7 October 2020

Published online: 27 November 2020

\section{References}

1. Division for Sustainable Development U-D. Sustainable Development Knowledge Platform. 2016. https://sustainabledevelopment.un.org/sdg3.

2. UNICEF. Neonatal mortality. UNICEF Data: Monitoring the situation of children and women. 2018. https://data.unicef.org/topic/child-survival/ neonatal-mortality/. Accessed 28 Jan 2019.

3. Hill K, Choi Y. Neonatal mortality in the developing world. Demogr Res. 2006;14:429-52.

4. Lawn JE, Kerber K, Enweronu-Laryea C, Bateman OM. Newborn survival in low resource settings - are we delivering? BJOG An Int J Obstet Gynaecol. 2009;116(SUPPL. 1):49-59. https://doi.org/10.1111/j.1471-0528.2009.02328.x.

5. Betjeman TJ, Soghoian SE, Foran MP. mHealth in sub-Saharan Africa. Int J Telemed Appl. 2013;7. https://doi.org/10.1155/2013/482324.

6. Lemay NV, Sullivan T, Jumbe B, Perry CP. Reaching remote health Workers in Malawi: baseline assessment of a pilot mHealth intervention. J Health Commun. 2012;17:105-17.

7. Adepoju 1-OO, Albersen BJA, De Brouwere $V$, van Roosmalen J, Zweekhorst M. mHealth for clinical decision-making in sub-Saharan Africa: a scoping review. JMIR mHealth uHealth. 2017;5:e38. https://doi. org/10.2196/mhealth.7185

8. Hall CS, Fottrell E, Wilkinson S, Byass P. Assessing the impact of mHealth interventions in low- and middle-income countries what has been shown to work? Glob Heal Action. 2014;7:1-12.

9. Agarwal S, Perry HB, Long L-A, Labrique AB. Evidence on feasibility and effective use of mHealth strategies by frontline health workers in developing countries: systematic review. Trop Med Int Heal. 2015;20:100314. https://doi.org/10.1111/tmi.12525.

10. McNabb M, Chukwu E, Ojo O, Shekhar N, Gill CJ, Salami H, et al. Assessment of the quality of antenatal care services provided by health 
workers using a mobile phone decision support application in northern Nigeria: a pre/post-intervention study. PLoS One. 2015;10. https://doi. org/10.1371/journal.pone.0123940.

11. Horner V, Rautenbach P, Mbananga N, Mashamba T, Kwinda H. An e-health decision support system for improving compliance of health workers to the maternity care protocols in South Africa. Appl Clin Inform. 2013;4:25-36. https://doi.org/10.4338/ACl-2012-10-RA-0044.

12. Catalani C, Green E, Owiti P, Keny A, Diero L, Yeung A, et al. A clinical decision support system for integrating tuberculosis and HIV Care in Kenya: a human-centered design approach. PLoS One. 2014;9:e103205. https://doi. org/10.1371/journal.pone.0103205.

13. Shao AF, Rambaud-Althaus C, Samaka J, Faustine AF, Perri-Moore S, Swai N, et al. New algorithm for managing childhood illness using mobile technology (ALMANACH): a controlled non-inferiority study on clinical outcome and antibiotic use in Tanzania. PLoS One. 2015;10:e0132316. https://doi.org/10.1371/journal.pone.0132316.

14. Zurovac D, Sudoi RK, Akhwale WS, Ndiritu M, Hamer DH, Rowe AK, et al. The effect of mobile phone text-message reminders on Kenyan health workers' adherence to malaria treatment guidelines: a cluster randomised trial. Lancet (London, England). 2011;378:795-803. https://doi.org/10.1016/ S0140-6736(11)60783-6.

15. Blank A, Prytherch H, Kaltschmidt J, Krings A, Sukums F, Mensah N, Zakane A, Loukanova S, Gustafsson LL, Sauerborn R, Haefeli WE. Quality of prenatal and maternal care: Bridging the know-do gap (QUALMAT study): an electronic clinical decision support system for rural Sub-Saharan Africa. BMC Med Inform Decis Mak. 2013;13:16. https://doi.org/10.1186/1472-6947-13-44.

16. Dalaba MA, Akweongo P, Aborigo RA, Saronga HP, Williams J, Blank A, et al. Cost-effectiveness of clinical decision support system in improving maternal health Care in Ghana. PLoS One. 2015;10:e0125920. https://doi.org/10.1371/ journal.pone.0125920.

17. Ghana Statistical Service (GSS), Ghana Health Service (GHS), and ICF. 2018. Ghana Maternal Health Survey 2017: Key Indicators Report. Accra, Ghana: GSS, GHS, and ICF

18. Issah K, Nang-Beifubah AOC. Maternal and neonatal survival and mortality in the upper west region of Ghana. Int J Gynaecol Obstet. 2011;113:208-10.

19. Howe LD, Manu A, Tawiah-Agyemang C, Kirkwood BR, Hill Z. Developing a community-based neonatal care intervention: a health facility assessment to inform intervention design. Paediatr Perinat Epidemiol. 2011;25:192-200.

20. Oduro-Mensah E, Kwamie A, Antwi E, Amissah Bamfo S, Bainson HM, Marfo $B$, et al. Care decision making of frontline providers of maternal and newborn health Services in the Greater Accra Region of Ghana. PLoS One. 2013;8:e55610. https://doi.org/10.1371/journal.pone.0055610.

21. Brown Amoakoh H, Klipstein-Grobusch K, Amoakoh-Coleman M, Agyepong IA, Kayode GA, Sarpong C, et al. The effect of a clinical decision-making mHealth support system on maternal and neonatal mortality and morbidity in Ghana: study protocol for a cluster randomized controlled trial. Trials. 2017;18. https://doi.org/10.1186/s13063-017-1897-4.

22. Ghana Statistical Service Accra, Ghana and Ghana Health Service Accra, Ghana and Macro International Inc. Calverton M. Ghana maternal health survey 2007. 2009. http://dhsprogram.com/publications/publication-fr227other-final-reports.cfm. Accessed 27 Jan 2016.

23. Ghana Statistical Service. 2010 population \& housing census summary report of final results. Accra, Ghana: Ghana Statistical Service; 2012. http:// www.statsghana.gov.gh/docfiles/2010phc/Census2010_Summary_report_ of_final_results.pdf.

24. Ghana Statistical Service (GSS), Ghana Health Service (GHS), and ICF International. 2015. Ghana Demographic and Health Survey 2014. Rockville, Maryland, USA: GSS, GHS, and ICF International.

25. Amoakoh, H.B., Klipstein-Grobusch, K., Amoakoh-Coleman, M. et al. The effect of a clinical decision-making mHealth support system on maternal and neonatal mortality and morbidity in Ghana: study protocol for a cluster randomized controlled trial. Trials. 2017;18:157. https://doi.org/10.1186/ s13063-017-1897-4.

26. Ghana Health Service Family Health Division. Ghana Health Service Family Health Division Annual Report 2016. Accra Ghana Health Service; 2017. https://www.ghanahealthservice.org/downloads/FHD_2016_ANNUAL_ REPORT_Final_June.19.2017natfinal.pdf. Accessed 27 Sep 2018.

27. Amoakoh-Coleman M, Agyepong IA, Zuithoff NPA, Kayode GA, Grobbee DE, Klipstein-Grobusch K, et al. Client factors affect provider adherence to clinical guidelines during first antenatal care. PLoS One. 2016;11:1-13. https://doi.org/10.1371/journal.pone.0157542.
28. Van Fenema E, Van Der Wee NJ, Bauer M, Witte CJ, Zitman FG. Assessing adherence to guidelines for common mental disorders in routine clinical practice. Int J Qual Health Care. 2012;24:72-9 http:// ovidsp.ovid.com/ovidweb.cgi?T=JS\&PAGE=reference\&D=emed10\&NEWS= $N \& A N=2012037128$

29. Browne JL, Van Nievelt SW, Srofenyoh EK, Grobbee DE, Klipstein-Grobusch K Criteria-based audit of quality of care to women with severe pre-eclampsia and eclampsia in a referral hospital in Accra, Ghana. PLoS One. 2015;10: e0125749. https://doi.org/10.1371/journal.pone.0125749.

30. Sales AE, Tipton EF, Levine DA et al. Are Co-Morbidities Associated with Guideline Adherence? The MI-Plus Study of Medicare Patients. J Gen Intern Med. 2009;24:1205-1210. https://doi.org/10.1007/s11606-009-1096-4.

31. StataCorp. Stata statistical software: release 13. College Station, TX: StataCorp LP; 2013. http://www.stata.com/support/faqs/resources/citingsoftware-documentation-faqs/. Accessed 28 Jan 2016.

32. NIH:US National Library of Medicine. Apgar score: MedlinePlus Medical Encyclopedia. https://medlineplus.gov/ency/article/003402.htm. Accessed 22 Feb 2019.

33. Oakley E. Using video recording to identify management errors in pediatric trauma resuscitation. Pediatrics. 2006;117:658-64. https://doi.org/10.1542/ peds.2004-1803.

34. Carbine DN, Finer NN, Knodel E, Rich W. Video recording as a means of evaluating neonatal resuscitation performance. Pediatrics. 2000;106:654-8. https://doi.org/10.1542/peds.106.4.654.

35. Lindbäck C, Ashish AC, Wrammert J, Vitrakoti R, Ewald U, Målqvist M. Poor adherence to neonatal resuscitation guidelines exposed; an observational study using camera surveillance at a tertiary hospital in Nepal. BMC Pediatr. 2014;14. https://doi.org/10.1186/1471-2431-14-233.

36. Chikuse B, Chirwa E, Maluwa A, Malata A, Odland J. Midwives' adherence to guidelines on the management of birth asphyxia in Malawi. Open J Nurs. 2012;02:351-7. https://doi.org/10.4236/ojn.2012.24052.

37. Amoakoh HB, Kerstin K-G, Evelyn A, Grobbee Diederick E, AIA YL. How and why frontline health workers (did not) use a multifaceted mHealth intervention to support maternal and neonatal health care decisionmaking in Ghana. BMJ Glob Heal. 2019;4:1153. https://doi.org/10.1136/ bmjgh-2018-001153.

38. Volpe JJ. Neurology of the newborn. 5th ed. Philadelphia, USA: Saunders/ Elsevier; 2008. https://books.google.com.gh/books?hl=en\&lr=\&id= RiPpqyaH7DIC\&oi=fnd\&pg=PP1\&ots=DOTmnlxFdh\&sig= 3YtJwni9YrfYVatICGwUdxS4UpU\&redir_esc $=y \# v=$ onepage\&q\&f=false.

39. van Rooij LGM, van den Broek MPH, Rademaker CMA, de Vries LS. Clinical Management of Seizures in newborns. Pediatr Drugs. 2013;15:9-18. https:// doi.org/10.1007/s40272-012-0005-1.

40. Johnson L, Bhutani VK, Karp K, Sivieri EM, Shapiro SM. Clinical report from the pilot USA kernicterus registry (1992 to 2004). J Perinatol. 2009;29:S25-45. https://doi.org/10.1038/jp.2008.211.

41. Wahabi HA, Alziedan RA. Reasons behind non-adherence of healthcare practitioners to pediatric asthma guidelines in an emergency department in Saudi Arabia. BMC Health Serv Res. 2012;12:226 http://www.biomedcentral. com/1472-6963/12/226. Accessed 21 Feb 2019..

42. Lin ND, Martins SB, Chan AS, Coleman RW, Bosworth HB, Oddone EZ, Shankar RD, Musen MA, Hoffman BB, Goldstein MK. Identifying barriers to hypertension guideline adherence using clinician feedback at the point of care. AMIA Annual Symposium proceedings. AMIA Symposium; 2006;494-498.

43. De La Sierra A, Zamorano JL, Ruilope LM. Application of hypertension guidelines in clinical practice: implementation of the 2007 ESH/ESC European practice guidelines in Spain. J Hypertens. 2009;27(SUPPL. 3):S2732. https://doi.org/10.1097/01.hjh.0000356769.32130.95.

44. Graphic Communications Group Ltd. Umbilical cord care in newborns, GHS receives medication - graphic online. 2018. https://www.graphic.com.gh/ news/health/umbilical-cord-care-in-newborns-ghs-receives-medication.html. Accessed 21 Feb 2019.

45. Ghana Health Service. Newborn Care Programme | Programmes | Ghana Health Service. 2017. http://www.ghanahealthservice.org/newborn/ programme-cat.php?ghspid=3\&ghscid=76. Accessed 21 Feb 2019.

46. Mullany LC, Darmstadt GL, Katz J, Khatry SK, Leclerq SC, Adhikari RK, Tielsch JM. Risk of mortality subsequent to umbilical cord infection among newborns of southern Nepal: cord infection and mortality. Pediatr Infect Dis J. 2009;28(1):17-20. https://doi.org/10.1097/INF.0b013e318181fb4c.

47. Moyer CA, Aborigo RA, Logonia G, Affah G, Rominski S, Adongo PB, et al. Clean delivery practices in rural northern Ghana: a qualitative study of 
community and provider knowledge, attitudes, and beliefs. 2012. doi: https://doi.org/10.1186/1471-2393-12-50,

48. Jones $\mathrm{COH}$, Wasunna B, Sudoi R, Githinji S, Snow RW, Zurovac D. "Even if you know everything you can forget": health worker perceptions of Mobile phone text-messaging to improve malaria case-Management in Kenya. PLoS One. 2012;7:e38636. https://doi.org/10.1371/journal.pone.0038636.

49. Amoakoh HB, Klipstein-Grobusch K, Agyepong IA, Zuithoff NPA, AmoakohColeman M, Kayode GA, et al. The effect of an mHealth clinical decisionmaking support system on neonatal mortality in a low resource setting: a cluster-randomized controlled trial. EClinicalMedicine. 2019;12:31-42.

\section{Publisher's Note}

Springer Nature remains neutral with regard to jurisdictional claims in published maps and institutional affiliations.

Ready to submit your research? Choose BMC and benefit from:

- fast, convenient online submission

- thorough peer review by experienced researchers in your field

- rapid publication on acceptance

- support for research data, including large and complex data types

- gold Open Access which fosters wider collaboration and increased citations

- maximum visibility for your research: over $100 \mathrm{M}$ website views per year

At $\mathrm{BMC}$, research is always in progress.

Learn more biomedcentral.com/submissions 